\title{
AN EXPERIMENTAL STUDY ON LIGHT TRANSMITTING CONCRETE
}

\author{
P.M.Shanmugavadivu ${ }^{1}$, V. Scinduja ${ }^{2}$, T.Sarathivelan ${ }^{3}$, C.V Shudesamithronn ${ }^{4}$ \\ ${ }^{I}$ Professor \& Head, Department of Civil Engineering, Knowledge Institute of Technology, Kakkapalayam, Salem, - \\ 637 504, Tamil Nadu, India \\ ${ }^{2}$ Assistant Professor, Department of Civil Engineering, Knowledge Institute of Technology, Kakkapalayam, Salem- \\ 637 504, Tamil Nadu, India \\ ${ }^{3}$ Assistant Professor, Department of Civil Engineering, Knowledge Institute of Technology, Kakkapalayam, Salem- \\ 637 504, Tamil Nadu, India \\ ${ }^{4}$ Assistant Professor, Department of Civil Engineering, Knowledge Institute of Technology, Kakkapalayam, Salem- \\ 637 504, Tamil Nadu, India
}

\begin{abstract}
Light transmitting concrete is one of the fibre reinforced concrete which is used for aesthetic application by incorporating the optical fibres in concrete. Optical fibres are one which helps for transmission of light through fibre. The end-lite type of fibre is used to increase the aesthetic appearance of the concrete. The concept of light transmitting concrete is like a transparent concrete. When it is used in ceiling or side wall, it is exposed to direct sun light which transmit the image but not completely transparent. The investigation is not constrained only with the decorative purpose but the effect of fibre application in the strength aspect is also discussed. When the fibres are arranged in different layers, that increases the load carrying capacity and also the patter can be created to make the concrete decorative. This type of concrete can be installed at a very low cost and increasing the visual appeal. The application can be used in decorating the interior of a hall or lobby and the ceiling to glow in dark by external lighting source and during day time the concrete glows by the light transmission from natural resource.
\end{abstract}

Keywords: Light transmitting concrete, Optical fibre, Transparent concrete

\section{INTRODUCTION}

With the economic growth and science-technology development, more and more large-scale civil engineering structures such as tall buildings, underground buildings and landmark buildings and so on are built around the world. While the economic growth is a kind of extensive growth: high input, high consumption and high pollution, for that the energy saving technology is low, especially in developing countries. The brightness of indoor environment is entirely maintained by artificial lighting, which has consumed a large number of resources. Moreover civil engineering structures always suffer from external environmental effects, economic loss and casualties are serious once damaged. And now, building energy saving and building safety have been attracted much attention. Optical fibre sensors such as fibre Bragg Grating, Brillouin distributed sensors and plastic optical fibre sensors have been widely used for the in situ monitoring of major projects. Meanwhile some new building materials are developed and used in structures, including self-diagnosis smart concrete, self-tuning smart concrete, self-repairing smart concrete, soundproof concrete, thermal insulation concrete and so on. All these functional materials only focus on the intelligence characteristics, and cannot possess energy saving. In 2001, the concept of transparent concrete is first put forward by Hungarian architect RonLosonzi, and the first transparent concrete block is successfully produced by mixing large amount of glass fibre into concrete in 2003, named as LiTraCon. LiTraCon ("light transmitting concrete") is a translucent concrete building material made of fine concrete embedded with $5 \%$ by weight of optical glass fibres. Litracon presents the concept of light transmitting concrete in the form of a widely applicable new building material. It can be used for interior or exterior walls, illuminated pavements or even in art or design objects. By impregnating the concrete with optical glass fibres, light can be transmitted from the outside in or inside out. This concrete has the same strength as regular concrete and will continue to transmit light through walls up to twenty meters (twenty-two feet) thick. A wall made of "LitraCon" has the strength of traditional concrete and an embedded array of glass fibres that can display a view of the outside world, such as the silhouette of a tree, for example. Thousands of optical glass fibres form a matrix and run parallel to each other between the two main surfaces of every block. Shadows on the lighter side will appear with sharp outlines on the darker one. Even the colours remain the same. This special effect creates the general impression that the thickness and weight of a concrete wall will disappear. The hope is that the new material will transform the interior appearance of concrete buildings by making them feel light and airy rather than dark and heavy. 


\section{LITERATURE STUDY}

Zhi Zhou et al(2006),reported that the light guiding performance of concrete materials is completely determined by the internal POFs area ratio and the surface roughness in certain sections. POF based transparent concrete could be regarded as an art which could be used in museums and specific exhibitions rather than just a construction material. Jianping $\mathrm{He}$ et al(2011),studied the excellent properties of light guiding and elasto-optic effect of optical fiber. To evaluate the effectiveness of smart transparent concrete and they concluded the transparent concrete has good light guiding property, and the POF volume ratio to concrete is proportion to transmission. The amount of POFs has seriously influenced the compressive strength of the corresponding concrete. The POFs have reduced the antipermeability of the concrete. Varshara in a et al(2013), investigated to develope the building a esthetic in modern construction and consumption of energy with eco-friendly way. The main purpose is to use sunlight as a light source to reduce the power consumption of illumination and to use the optical fibre to sense the stress of structures and also this concrete as an architectural purpose for good aesthetical view of the building. They conclude that the not looses the strength parameter when compared to regular concrete. This kind of building material can integrate the concept of green energy saving with the usage self-sensing properties of functional material. BasmaF.Bashbashet al(2013), discussed about the development of a light transmitting concrete using plastic optical fibre, which will help to reduce the consumption of electric energy. They concluded that an optical fibre can be easily combined with concrete and that the POF could provide a steady light transmitting ratio. The smart transparent concrete can be regarded as a green energy saving construction material.

\section{SIGNIFICANCE OF THE STUDY}

To make the concrete decorative by luminating on the surface

To check whether the introduction of fibre wire into concrete will help or influence to change in the engineering properties of the member.

\section{EXPERIMENTAL INVESTIGATION}

\subsection{Materials Used}

Portland Pozzolana cement, Natural sand and Optical fibre.

The diameter of the fibre available in market is given below.

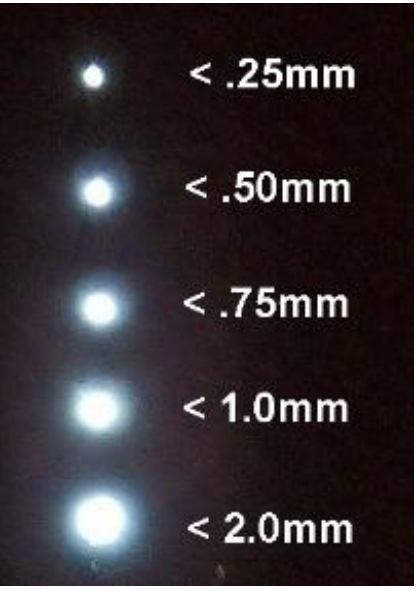

\subsubsection{Benefits of Optical Fibre}

- Safe - No electricity, heat, or ultraviolet light in the fibre optic cable. Ideal for use in and around water, precious artifacts, paintings, combustible surfaces, etc.

- Versatile- Multiple applications possible from one light source.

- Economical- Operates on less than two amps.

- User friendly- The cable is durable, UV protected plastic, so there is nothing to break or burn out. Virtually maintenance free.

\subsection{Mix Proportions}

Mix proportions are arrived as follows: Cement $-360 \mathrm{~kg}$, Sand $-560 \mathrm{~kg}$, Fibre $-4.5 \mathrm{~kg}$, Water $-190 \mathrm{lit}$

\subsection{Placing of Fibres and Casting the Concrete}

Initially the fibres are arranged in the required pattern in the formwork before casting of concrete. Fixing of fibres done in a plastic sheet and behind this thermo coal is placed to hold it. After installation of fibre, one end is connected to the lighting source and other end is left free on the surface of the concrete which is to be casted. Then the wet mix is applied on the slab mould prepared. Allow the concrete to cure for 7-15 days. After curing, these slabs will transmit light on its surface. Fibres are glowing at end by giving light source on another end of the fibres. It is shown in Figure 1.

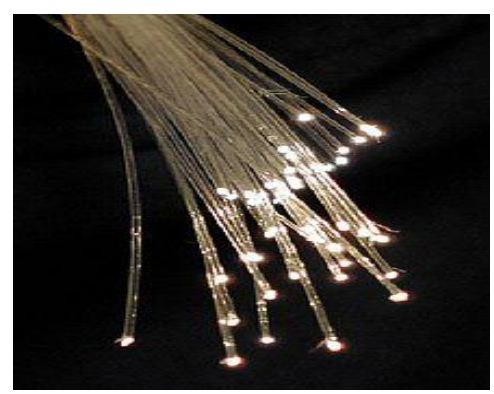

a) 


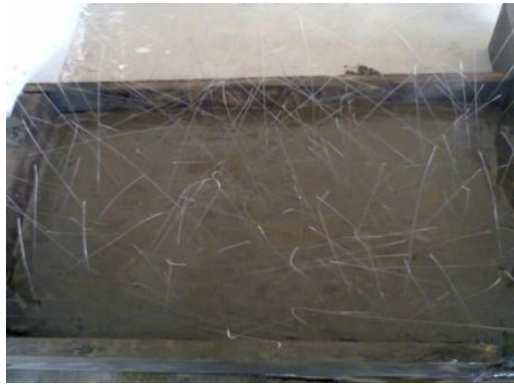

b) Placing of Fibre

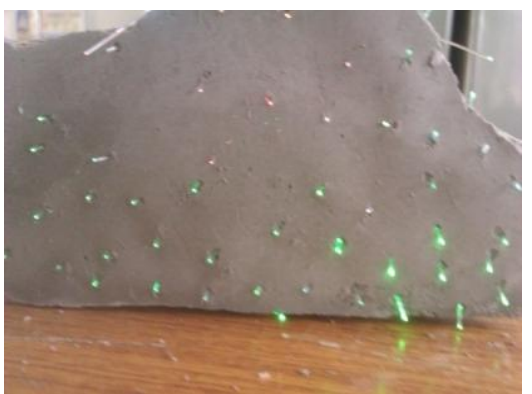

c) Transmission of light

Fig - 1: Placing of fibre in concrete

\subsection{Workability}

The workability of the concrete is determined by conducting the slump cone test.

\subsection{Compressive Strength}

By definition, the compressive strength of a material is that value of uniaxial compressive stress reached when the material fails completely. The compressive strength is usually obtained experimentally by means of a compressive test. The compressive strength of the concrete is determined by cast the cubes of size $150 \mathrm{~mm} \times 150 \mathrm{~mm} \times 150 \mathrm{~mm}$.

\section{Compressive strength $=$ load/area}

[eq.1]

\subsection{Flexural Strength}

The flexural strength of the concrete is determined by conducting the test on prism by two point loading.

$$
\text { Flexural strength }=\mathbf{P l} / \mathbf{b d}^{2}
$$

Where, $\mathrm{P}$ - Load, 1 - Length of the specimen, $\mathrm{b}$ - width of the prism, $\mathrm{d}$ - depth of the prism

\subsection{RESULTS AND DISCUSSIONS}

\subsection{Workability}

The workability of the concrete is determined by conducting the slump cone test and the observed slump is $92 \mathrm{~mm}$.

\subsection{Compressive Strength}

The compressive strength of the conventional concrete and light transmitting concrete in 7,14 and 28 daysis shown in Figure 2

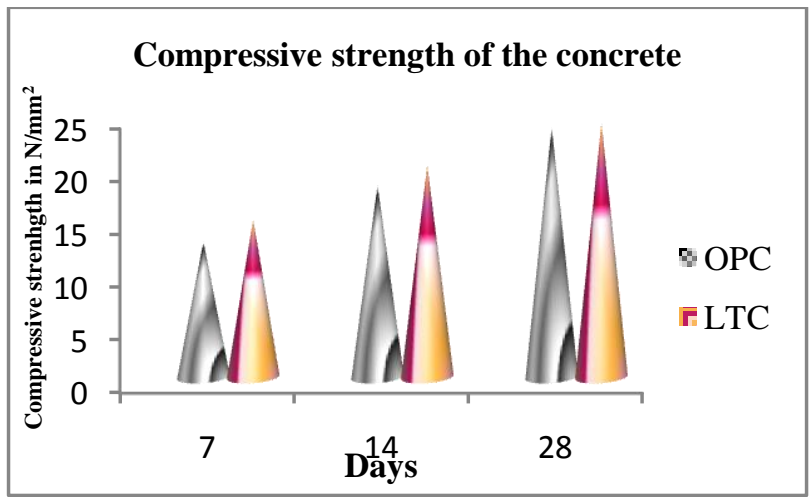

Fig - 2: Compressive strength of the concrete

\subsection{Flexural Strength}

The flexural strength of the conventional concrete and light transmitting concrete in 7, 14 and 28 days is shown in Figure 3.

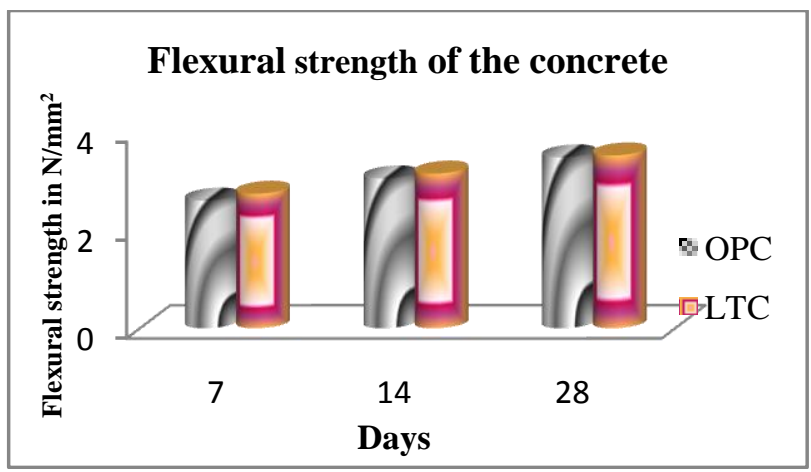

Fig - 3: Flexural strength of the concrete

The strength results of decorative concrete are correlated with results of ordinary plain cement concrete.The results evidently show that the decorative concrete also performance based on the strength aspect is also considerably high. Hence the application of optical fibre will make the concrete decorative as well as can make the concrete structural efficient.

\section{CONCLUSIONS}

- The efficiency of the application of optical fibre is studied by comparing the strength with the normal M20 grade concrete and the test results proved that the efficiency is more in all aspect.

- The fibres can be used in concrete for decorative purpose.

- $\quad$ The major purpose of light transmitting concrete is created as a model and the light transmission is made of the illuminating side of the concrete.

- This decorative concrete can be used in interior design of buildings as panels in slabs, walls etc. 
- The decorative concrete can be used in place of windows because it can transmit the sunlight.

- Hence the application of optical fibre will make the concrete decorative as well as can make the concrete structural efficient.

\section{ACKNOWLEDGEMENTS}

The authors would like to thank Dinesh kumar, Gayathri, Ramesh and Suvitha, students of Knowledge Institute of Technology, Salem

\section{REFERENCES}

[1]. Basma F. Bashbash. (2013). "Basics of light Transmitting Concrete", pp 079-083, (2013)

[2]. Jianping He. (2011). "Study on Smart Transparent Concrete Product and its performances", $6^{\text {th }}$ international workshop on advanced smart materials and smart structures technology, (2011)

[3]. IS: 10262-1982 Recommended Guidelines for Concrete Mix Design.

[4]. SANTHAKUMAR.A.R, "Concrete Technology", Oxford Publishing \& Co., New Delhi, 2007, First Edition.

[5]. Varsharaina. (2013). "A Study on Transparent Concrete: ANovel Architectural Material to Explore Construction Sector", International Journal of Engineering and Innovative Technology, volume 2, issue 8, pp83-87, (2013)

[6]. Zhizhou. (2006). "Research and Development of Plastic Optical Fibre Based Smart Transparent Concrete", Proceedings of SPIE, vol. F -1, pp. 7293 72930, (2006)

\section{BIOGRAPHIES}

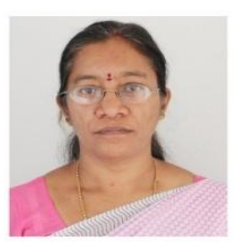

Dr.P.M. Shanmugavadivu is presently working as Professor and head in the department of Civil Engineering at Knowledge Institute of Technology. She has more than 20 years of teaching experience. She has published more than 45 papers in the reputed International and National journals $\&$ Conferences. She won the Best Papers Award in the International Conferences and Best Teacher Award in the year $2003-2004$.

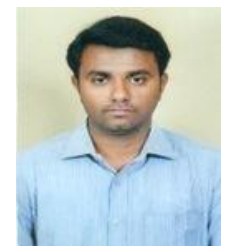

Mr.C.V.Shudesamithronn is presently working as Assistant Professor in the Department of Civil Engineering at Knowledge Institute of Technology. He has more than 3 years of teaching experience. He has published 1 paper in the International Conference and 3 papers in the National Conferences.

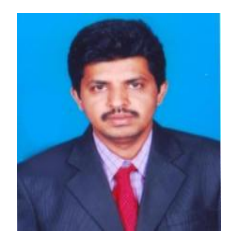

Mr.T.Sarathivelan is presently working as Assistant Professor in the Department of Civil Engineering at Knowledge Institute of Technology. He has more than 3 years of teaching experience and 10 years of Industrial experience. He has published 1 paper in the International Conference and 3 papers in the National Conferences.

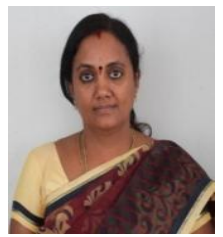

Mrs.V.Scinduja is presently working as Assistant Professor in the Department of Civil Engineering at Knowledge Institute of Technology. She has more than one year of teaching experience. She has published 1 paper in the International Conference and 2 papers in the National Conferences. 